\section{BRAZIULIAN JOURNAL}

OF MEDICAL AND BIOLOGICAL RESHARCH

www.bjournal.com.br
ISSN 0100-879X

Volume 43 (9) 812-913 September 2010

BIOMEDICAL SCIENCES

AND

CLINICAL INVESTIGATION

Braz J Med Biol Res, September 2010, Volume 43(9) 860-868

doi: 10.1590/S0100-879X2010007500081

Human monocytes tolerant to LPS retain the ability to phagocytose bacteria and generate reactive oxygen species

M.L. Fernandes, M.E. Mendes, M.K.C. Brunialti and R. Salomão

The Brazilian Journal of Medical and Biological Research is partially financed by
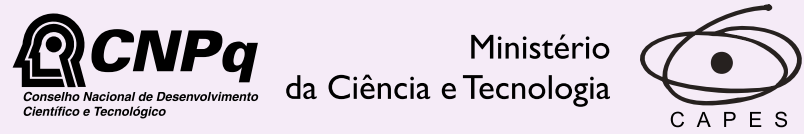

Ministério da Educação

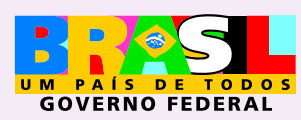

TFAPESP

Institutional Sponsors
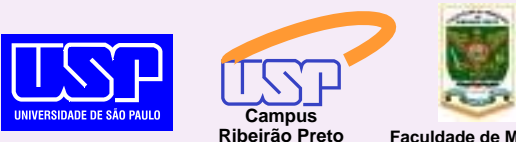

Ф SHIMADZU

GE Healthcare
Hotsite of proteomics metabolomics developped by: 


\title{
Human monocytes tolerant to LPS retain the ability to phagocytose bacteria and generate reactive oxygen species
}

\author{
M.L. Fernandes, M.E. Mendes, M.K.C. Brunialti and R. Salomão \\ Laboratório de Imunologia, Divisão de Moléstias Infecciosas, Escola Paulista de Medicina, \\ Universidade Federal de São Paulo, São Paulo, SP, Brasil
}

\begin{abstract}
Tolerance to lipopolysaccharide (LPS) occurs when animals or cells exposed to LPS become hyporesponsive to a subsequent challenge with LPS. This mechanism is believed to be involved in the down-regulation of cellular responses observed in septic patients. The aim of this investigation was to evaluate LPS-induced monocyte tolerance of healthy volunteers using whole blood. The detection of intracellular IL-6, bacterial phagocytosis and reactive oxygen species (ROS) was determined by flow cytometry, using anti-IL-6-PE, heat-killed Staphylococcus aureus stained with propidium iodide and 2',7'-dichlorofluorescein diacetate, respectively. Monocytes were gated in whole blood by combining FSC and SSC parameters and CD14-positive staining. The exposure to increasing LPS concentrations resulted in lower intracellular concentration of IL-6 in monocytes after challenge. A similar effect was observed with challenge with MALP-2 (a Toll-like receptor (TLR)2/6 agonist) and killed Pseudomonas aeruginosa and $S$. aureus, but not with flagellin (a TLR5 agonist). LPS conditioning with $15 \mathrm{ng} / \mathrm{mL}$ resulted in a $40 \%$ reduction of IL-6 in monocytes. In contrast, phagocytosis of $P$. aeruginosa and $S$. aureus and induced ROS generation were preserved or increased in tolerant cells. The phenomenon of tolerance involves a complex regulation in which the production of IL-6 was diminished, whereas the bacterial phagocytosis and production of ROS was preserved. Decreased production of proinflammatory cytokines and preserved or increased production of ROS may be an adaptation to control the deleterious effects of inflammation while preserving antimicrobial activity.
\end{abstract}

Key words: IL-6, ROS; Phagocytosis; MALP-2; Flagellin; LPS tolerance

\section{Introduction}

Challenge with lipopolysaccharide (LPS) induces a wide range of biological responses in susceptible animals, including the synthesis and release of inflammatory cytokines, reactive oxygen species (ROS) and reactive nitrogen species (1). The biological activity of LPS may be modulated in vivo, and hypersensitivity and tolerance may be induced under experimental conditions (2).

The pre-exposure of an animal to low doses of LPS inhibits the biological response to a re-exposure to high doses of LPS, reducing the pathophysiological changes that are observed in normal hosts. Similar effects are also observed in cell cultures by re-exposure to LPS in vitro. This phenomenon is called endotoxin tolerance, although other terms such as reprogramming, adaptation, anergy, or refractoriness are used in the literature (3).

Tolerance to endotoxin has been examined in a series of elegant experiments. It has been reported that periph- eral blood cells of healthy humans exposed to LPS in vivo showed reduced production of tumor necrosis factor-alpha (TNF- $\alpha$ ), interleukin (IL)-1 $\beta$, IL-6, and IL-10 after further stimulation in vitro $(4,5)$. Tominaga et al. (6) found a lower expression of mRNA for TNF- $\alpha$ and IL- 6 in macrophages of tolerant mice in response to re-stimulation with LPS. However, other in vivo and in vitro studies evaluating endotoxin tolerance have shown that the phenomenon is not a global down-regulation of macrophages, but a complex modulatory response. The re-exposure of monocytes and macrophages previously exposed to LPS showed lower gene expression of TNF- $\alpha, \mathrm{IL}-1 \beta, \mathrm{IL}-6, \mathrm{IL}-12$, and Jun $\mathrm{B}$, but other genes, including IL-10, IL-1R and tumor necrosis factor receptor II (TNFRII), are normally or highly expressed (for a review, see Ref. 7).

Studies on circulating leukocytes of septic patients have shown reduced production of inflammatory cytokines after

Correspondence: R. Salomão, Laboratório de Imunologia, EPM, UNIFESP, Rua Pedro de Toledo, 781, 15ํandar, 04039-032

São Paulo, SP, Brasil. Fax: +55-11-5081-5394. E-mail: rsalomao@unifesp.br

Received March 20, 2010. Accepted August 2, 2010. Available online August 20, 2010. Published September $13,2010$. 
in vitro stimulation, similar to what is found in cells made tolerant to LPS. Ertel et al. (8), using whole blood from septic patients, found a smaller production of TNF- $\alpha$, IL-1 $\beta$, and IL-6 after stimulation with LPS. This reduced cytokine production was extended to IL-4, IL-10, IL-12, interferongamma (IFN-Y), and transforming growth factor-beta (TGF- $\beta$ ) (9). A study conducted by our group using a similar model confirmed the decreased production of TNF- $\alpha$ and IFN-y in vitro; however, we found preserved production of IL-10 in patients with severe sepsis and septic shock (10). Brunialti et al. (11) demonstrated a positive regulation of the production of inflammatory cytokines at the onset of sepsis, followed by a prominent decline in more severe stages of the disease, severe sepsis and septic shock, showing that the cellular response may be modulated according to the stages of sepsis.

The induction of the phenotype of tolerance to endotoxin may be triggered by other family members of Toll-like receptors (TLR)/IL-1R ligands, in addition to LPS and TLR4. The ability of a stimulus other than LPS to initiate the phenotype of tolerance is called cross-tolerance (12). Medvedev et al. (13) showed that pretreatment with IL-1 $\beta$ resulted in inhibition of activation of NF-KB and AP-1 in response to LPS. The conditioning of macrophages with other bacterial products such as lipoteichoic acid resulted in inhibited secretion of LPS-induced TNF- $\alpha$ (14).

Invading pathogens are phagocytized and killed by a powerful arsenal of enzymes, cationic proteins, ROS, and reactive nitrogen species produced by the cell and released into the phagosomes (1). In animal models, in vivo and in vitro experiments have shown preserved phagocytosis and bacterial clearance in tolerant cells $(15,16)$, while both reduced $(17)$ and enhanced $(18,19)$ nitric oxide (NO) generation has been reported.

In a previous study by our group involving patients with severe sepsis and septic shock, we observed lower production of inflammatory cytokines by mononuclear cells after in vitro stimulation with LPS (11). However, the production of ROS in the same patients was increased in monocytes under basal conditions and after stimulation with PMA, fMLP, LPS, and Staphylococcus aureus compared to healthy volunteers (20). This finding revealed a dichotomy of the monocyte response in septic patients with downregulation of the production of inflammatory cytokines and up-regulation of ROS.

Since there are similarities between the functional modulations found in leukocytes of septic patients and in cells made tolerant to LPS, we investigated whether the same phenomenon occurs in tolerance induced in human whole blood in vitro.

\section{Material and Methods}

\section{Healthy volunteers \\ The study was approved by the Ethics Research Com-}

mittee of Universidade Federal de São Paulo, Hospital São Paulo (protocol \#0121/06). Written informed consent was obtained from all volunteers. Blood samples from 17 healthy volunteers (mean age, $29 \pm 8$ years; $82 \%$ females) were drawn into heparin-treated vacuum tubes (Becton Dickinson, UK). All volunteers reported being healthy and none were taking medication.

\section{Reagents}

LPS from Salmonella abortus equi, prepared by the phenol-water method and further purified with phenolchloroform-petroleum ether as previously described (21), was a gift from C. Galanos (Max-Planck Institute of Immunobiology, Germany). Macrophage-activating lipopeptide-2 (MALP-2) and flagellin were purchased from Alexis Biochemicals, Germany. Pseudomonas aeruginosa (ATCC 27853) was purchased from Chrisope Technologies, UK, and S. aureus (ATCC 25923) was purchased from Difco, USA. The following monoclonal antibodies were used: CD66b-fluorescein isothyocyanate (FITC), clone G1OF5; CD14-peridinin-chlorophyll-protein (PerCP), clone MФP9; anti-IL-6-phycoerythrin (PE), clone AS14 (BD Bioscience, USA).

\section{Induction of tolerance by LPS pretreatment}

Heparinized blood was diluted 1:2 in RPMI (Sigma, USA) and divided into 2-mL aliquots. Samples were pretreated with increasing concentrations of LPS: 1, 7.5, 15, and 30 $\mathrm{ng} / \mathrm{mL}$, or without LPS. After $18 \mathrm{~h}$ of incubation at $5 \% \mathrm{CO}_{2}$ at $37^{\circ} \mathrm{C}$, the samples were mixed and divided into 4 aliquots (500 $\mu \mathrm{L}$ each) and then challenged with different TLR agonists (LPS, MALP-2, flagellin) or Gram-positive (S. aureus) and Gram-negative ( $P$. aeruginosa) bacteria (Figure 1$)$.

\section{Intracellular detection of cytokines in monocytes in whole blood}

After challenge with different TLR agonists, samples were transferred to 5-mL propylene tubes and incubated at $37^{\circ} \mathrm{C}$ in the presence of $5 \% \mathrm{CO}_{2}$ for $5 \mathrm{~h}$ for intracellular detection of IL-6. After $30 \mathrm{~min}, 2 \mu \mathrm{L} 1 \mathrm{mM}$ monensin was added to the samples. Two hundred microliters of whole blood was washed in $2 \mathrm{~mL}$ phosphate-buffered saline (PBS) and centrifuged at $2500 \mathrm{~g}$ for $5 \mathrm{~min}$ at $4^{\circ} \mathrm{C}$. Red blood cells were ruptured with $2 \mathrm{~mL}$ lysis solution (FACS lysing solution, BD Bioscience) for $10 \mathrm{~min}$ in the dark at room temperature followed by centrifugation at $2500 \mathrm{~g}$ for $5 \mathrm{~min}$ at $4^{\circ} \mathrm{C}$. After washing with $2 \mathrm{~mL}$ PBS, samples were incubated with fluorochrome-conjugated monoclonal antibodies, CD66bFITC and CD14-PerCP, for surface staining for $15 \mathrm{~min}$ in the dark at room temperature. After centrifugation, the samples were washed in $2 \mathrm{~mL}$ PBS, centrifuged, and fixed with 1 $\mathrm{mL}$ fixation buffer (PBS 4\% paraformaldehyde) for $20 \mathrm{~min}$ in the dark at $4^{\circ} \mathrm{C}$. After centrifugation, the supernatants were discarded, and $50 \mu \mathrm{L}$ permeabilization buffer was then added (PBS 1\% FCS; $0.1 \%$ sodium azide; $0.1 \%$ saponin) 
plus anti-IL-6-PE. The tubes were incubated for $30 \mathrm{~min}$ in the dark at $4^{\circ} \mathrm{C}$. After this time, the samples were washed with $2 \mathrm{~mL}$ permeabilization buffer and centrifuged. Supernatants were discarded and cells were suspended in 0.3 $\mathrm{mL}$ PBS $1 \%$ sodium azide.

Event acquisition and analyses were performed using the CellQuest software (BD Bioscience) and a FACSCalibur four-color flow cytometer (BD Bioscience). For each condition 5000 events were acquired using forward- and side-scatter parameters combined with CD14-positive cells and CD66bnegative cells. All events were acquired and stored.

\section{Analysis of phagocytosis in tolerant and non-tolerant monocytes in whole blood}

Phagocytosis was detected using heat-killed $S$. aureus stained with propidium iodide (PI; Sigma). Briefly, after inactivation at high temperature, the bacteria were incubated with $\mathrm{PI}$ (5\% concentrated) for $30 \mathrm{~min}$ in the dark at room temperature. The bacteria suspension was washed, resuspended in glycoside PBS solution and stored in aliquots of $2.4 \times 10^{9}$ / $\mathrm{mL}$ at $-20^{\circ} \mathrm{C}$ until use. An aliquot $(100 \mu \mathrm{L})$ of Pl-labeled $S$. aureus was added to $200 \mu \mathrm{L}$ whole blood, pretreated or not with LPS for $18 \mathrm{~h}$, and $700 \mu \mathrm{L}$ PBS (Figure 1). The samples were incubated at $37^{\circ} \mathrm{C}$ in a shaking water bath for $30 \mathrm{~min}$. Thereafter, $2 \mathrm{~mL}$ PBS $3 \mathrm{mM}$ EDTA (Sigma) was added to each tube followed by centrifugation at $250 \mathrm{~g}$ for $5 \mathrm{~min}$ at $4^{\circ} \mathrm{C}$. Hypotonic lyses in saline (0.2 and 1.6\%, Merck, Germany) were performed followed by centrifugation. Finally, the supernatant was discarded and pellets were stained with $6 \mu \mathrm{L}$ CD14-PerCP.After centrifugation, pellets were suspended in $0.3 \mathrm{~mL}$ PBS $3 \mathrm{mM}$ EDTA for flow cytometry analysis.

Monocytes were identified by side scatter and forward scatter parameters combined with positive staining for CD14. Monocyte phagocytosis was shown as the per- centage of Pl-stained cells and as the geometric mean of fluorescence intensity (GMFI).

Analysis of monocyte oxidative burst in whole blood after pretreatment with LPS and challenge with LPS, $S$. aureus or $P$. aeruginosa

Oxidative burst was quantified by measuring the oxidation of 2', 7'-dichlorofluorescein diacetate (DCFH-DA, Sigma) in whole blood after pretreatment and challenge (Figure 1). Tubes containing $200 \mu \mathrm{L}$ whole blood, stimuli, $200 \mu \mathrm{L} 0.3$ $\mathrm{mM}$ DCFH-DA and PBS to complete $1 \mathrm{~mL}$ were incubated at $37^{\circ} \mathrm{C}$ in a shaking water bath for $30 \mathrm{~min}$. The stimuli added were LPS $(250 \mathrm{ng} / \mathrm{mL})$, S. aureus $\left(24 \times 10^{6} / \mathrm{mL}\right)$ or $P$. aeruginosa $\left(12 \times 10^{6} / \mathrm{mL}\right)$. The samples were processed as described above.

Monocytes were identified by side scatter and forward scatter parameters and positive staining for CD14. ROS generation was shown in histograms and reported as the GMFI.

\section{Statistical analysis}

The Kolmogorov-Smirnov test was applied to determine whether distribution was normal. Continuous variables were described as median and range and represented in box-plot graphs. Differences among groups were tested by ANOVA plus the Bonferroni's post hoc test. A P value of $\leq 0.05$ was considered to be significant. Analysis was performed using the SPSS package, version 13.0 (USA).

\section{Results}

\section{Production of IL- 6 by monocytes conditioned with increasing concentrations of LPS and challenged with different TLR agonists and whole bacteria}

Peripheral blood cells were conditioned with small doses

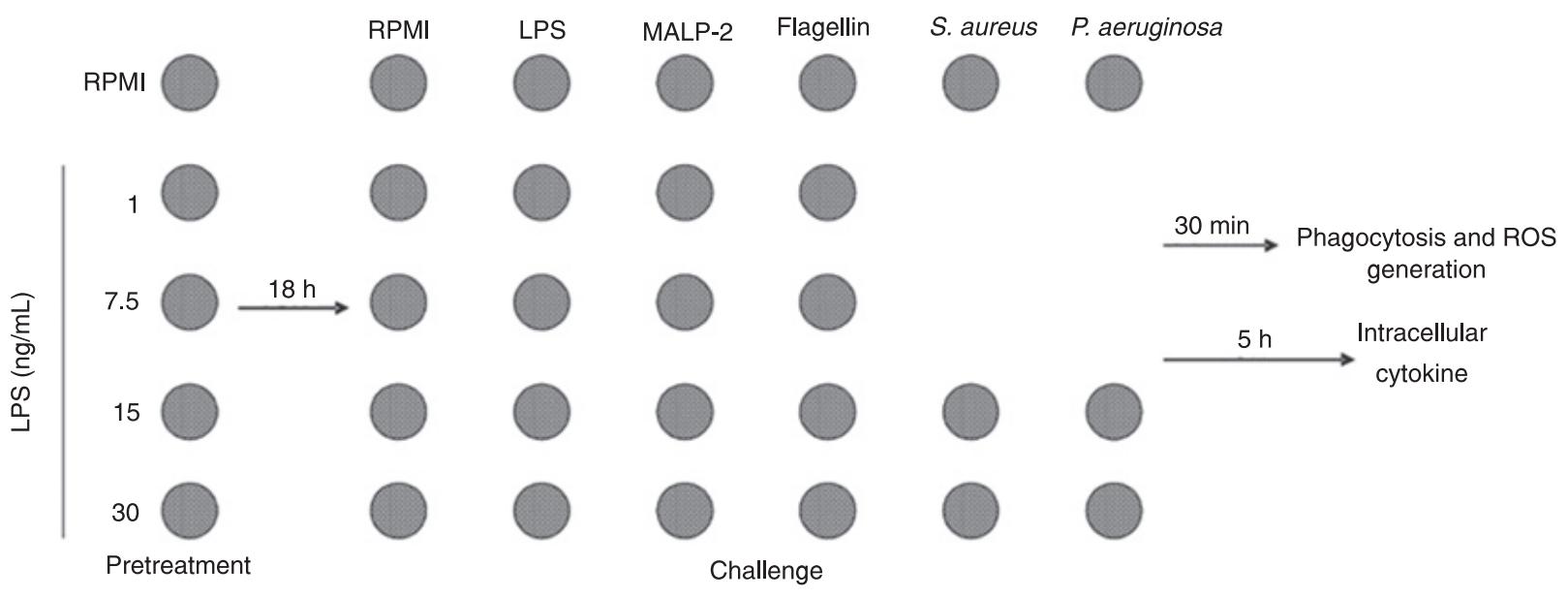

Figure 1. Schedule for the induction of tolerance in vitro. Heparinized blood was diluted 1:2 in RPMI and divided into aliquots. To induce tolerance, the samples were incubated with low concentrations of lipopolysaccharide (LPS) or without LPS (control). After 18 h of incubation, samples were re-stimulated with different TLR agonists. Then, production of interleukin-6, phagocytosis and reactive oxygen species (ROS) generation in monocytes was measured by flow cytometry. MALP-2 = macrophage-activating lipopeptide-2. 
of LPS and challenged with different TLR agonists: LPS (TLR4), MALP-2 (TLR2/6), flagellin (TLR5), and whole Gram-negative ( $P$. aeruginosa) and Gram-positive ( $S$. aureus) killed bacteria.

Detection of IL-6 in monocytes in whole blood was modulated by conditioning with low LPS concentrations $(P<0.001)$. Pre-exposure of peripheral blood to the concentrations of 7.5 and $30 \mathrm{ng} / \mathrm{mL}$ LPS resulted in a lower detection of intracellular IL-6 in monocytes after challenge with $100 \mathrm{ng} / \mathrm{mL}$ LPS compared to the detection in non-conditioned monocytes $(P<0.05$; Figure 2A). Pre-exposure to LPS also led to a decreased IL-6 production by monocytes after challenge with a TLR2/6 agonist (MALP-2; $P<0.001$ ). Conditioning with 15 and 30 $\mathrm{ng} / \mathrm{mL}$ LPS resulted in the detection of less intracellular IL-6 in monocytes after challenge with MALP-2 compared to control non-conditioned cells $(P<0.05$; Figure $2 B$ ). Increasing concentrations of LPS used for pre-exposure resulted in greater inhibition of IL-6 production. Accordingly, a decrease in the detection of the cytokine was found at a dose of $30 \mathrm{ng} / \mathrm{mL}$ in comparison to conditioning with $7.5 \mathrm{ng} / \mathrm{ml}$ LPS $(\mathrm{P}<0.05$; Figure $2 \mathrm{~B})$. When the TLR5 agonist flagellin was used as the challenge stimulus on monocytes conditioned with different concentrations of LPS no decrease in the production of IL- 6 was observed $(P=0.946$; Figure 2C).

Pre-exposure of monocytes to LPS modulated the induction of IL-6 by $S$. aureus $(P=0.001)$ and $P$. aeruginosa $(P<0.001)$. Conditioning with concentrations of 15 and $30 \mathrm{ng} / \mathrm{mL}$ LPS resulted in a lower detection of intracellular IL-6 in monocytes after challenge with $S$. aureus $(P<$ 0.05 ; Figure 2D) and $P$. aeruginosa $(P<0.05$; Figure $2 \mathrm{E})$ compared to the detection in cells without conditioning.

\section{Analysis of phagocytosis in tolerant and non-tolerant monocytes in whole blood}

No difference in phagocytosis of PI-labeled S. aureus was found between monocytes conditioned with 7.5 and $15 \mathrm{ng} / \mathrm{mL}$ LPS and without pre-exposure to LPS in the percentage of positive-stained monocytes ( $P=0.956$; Figure $3 \mathrm{~A}$, left) or in the intensity of fluorescence of $S$. aureus phagocytosing cells $(P=0.263$; Figure $3 A$, right).

\section{ROS production by tolerant and non-tolerant monocytes in whole blood}

ROS generation after LPS challenge $(250 \mathrm{ng} / \mathrm{mL})$ was similar in monocytes conditioned with 7.5 and $15 \mathrm{ng} / \mathrm{mL}$ (GMFI: median $=27.8$, range $=19.7-35.8$, and median $=$ 40.0 , range $=28.2-68.4$, respectively) compared to nonconditioned monocytes (GMFI: median $=28.5$, range $=$ 16.5-39.9; $P=0.162$ ). Pre-exposure to LPS and challenge with $S$. aureus $(P=0.05$; Figure $3 B$, left) resulted in increased ROS generation in monocytes while no difference was found with challenge with $P$. aeruginosa $(P=0.217$; Figure 3B, right).

\section{Discussion}

We evaluated the tolerance to LPS and cross-tolerance to other TLR agonists in monocytes present in human whole blood, thus mimicking the microenvironment of LPS-cell interaction as it occurs in vivo. Information about the effects of tolerance at the cellular level, measured by production of IL-6, phagocytosis and ROS generation by monocytes, was obtained using flow cytometry. Previous studies of induction of in vitro tolerance have evaluated macrophages and cells of different mouse tissues $(6,8)$, and peripheral blood mononuclear cells, alveolar macrophages or blood from healthy individuals $(4,5,11)$ exposed in vivo and in vitro to LPS.

Studies with monocytes and macrophages of patients with severe sepsis and septic shock showed reduced production of inflammatory cytokines after in vitro stimulation with LPS (8-10), a phenomenon that has similarities to tolerance induced by pre-exposure to LPS (3).

One hypothesis to explain this phenomenon would be the modulation of soluble proteins or cell surface receptors that are responsible for LPS carrying and cell recognition. Accordingly, previous reports have shown changes in plasma concentrations of proteins regulating the biological action of LPS (22) and decreased expression of CD14 on the surface of monocytes (23), among others. Nomura et al. (24) studied the expression of TLR4 in macrophages of mice tolerant to LPS and found a correlation between the reduction in the expression of TLR4 and the fall in production of IL-6, indicating a modulation at the cell membrane level. A previous study by our group showed no difference in the binding of LPS to the cell membrane of monocytes of septic patients compared to healthy individuals. However, there was a significant impairment of TNF- $\alpha$ production, detected intracellularly in monocytes by flow cytometry, suggesting that regulation occurs in the cell signaling cascade $(25,26)$.

Our results show that pre-exposure to small amounts of LPS was able to induce tolerance in peripheral blood monocytes in whole blood of human volunteers challenged with high concentrations of LPS. Other studies using human peripheral blood cells showed a reduced production of inflammatory cytokines $(4,5)$. The decreased response to LPS can be explained by the presence of several intracellular proteins that suppress the inflammatory response, regulating the cascade of negative signaling, and by different combinations of NF-KB hetero- and homodimers that modulate gene expression under inflammatory or endotoxintolerant conditions (for a review, see Ref. 27). In addition to the idea of blocking the signaling and gene transcription, it has been proposed that the tolerance phenotype is caused by increased production of anti-inflammatory factors (28). Recently, it was demonstrated that another mechanism is involved in tolerance, comprising epigenetic changes able to regulate the expression of isolated genes from a pathway (29). 

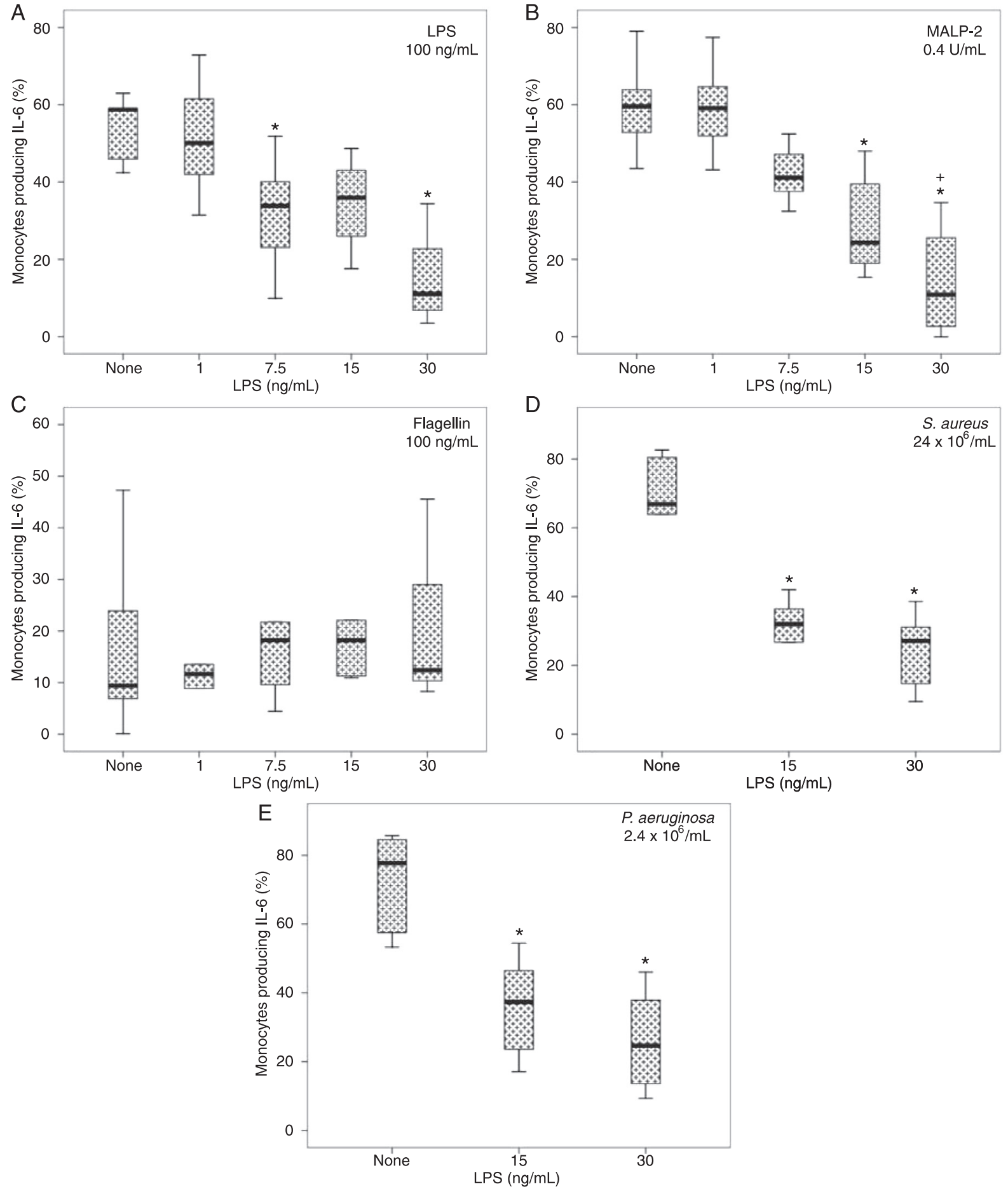

Figure 2. Interleukin-6 (IL-6) detection in monocytes conditioned with lipopolysaccharide (LPS) and challenged with Toll-like receptor (TLR) agonists and whole bacteria. Peripheral blood cells were conditioned with low concentrations of LPS for $18 \mathrm{~h}$ and challenged with different TLR agonists: LPS (TLR4) (A), macrophage-activating lipopeptide-2 (MALP-2) (TLR2/6) (B), flagellin (TLR5) (C), and whole Gram-positive (S. aureus) (D) and Gram-negative ( $P$. aeruginosa) (E) killed bacteria. For the detection of intracellular IL-6, whole blood samples were stimulated for $6 \mathrm{~h}$. Monocytes were identified by forward scatter and side scatter parameters, CD14-positive staining and intracellular detection of IL-6 on monocytes performed by flow cytometry. ${ }^{*} \mathrm{P}<0.05$ compared to no pretreatment (ANOVA followed by the Bonferroni's test). ${ }^{+} \mathrm{P}<0.05$ compared to pretreatment with $7.5 \mathrm{ng} / \mathrm{mL}$ LPS (ANOVA followed by the Bonferroni's test). $\mathrm{N}=5$ for three different experiments. 
Once tolerance was demonstrated to LPS, a TLR4 agonist, in the model of whole blood in vitro, we tested whether this effect occurs with TLR2/6 and TLR5 agonists. The pre-exposure to LPS led to a reduction of IL-6 production in peripheral blood monocytes after challenge with the TLR2/6 agonist MALP-2. This finding agrees with Sato and colleagues (30), who observed reduced production of TNF- $\alpha$ in peritoneal macrophages of mice pre-exposed to LPS and challenged with MALP-2. However, the production of this cytokine was increased when both MALP-2 and LPS were simultaneously added to the culture of peritoneal macrophages, showing a synergistic effect between these agonists. Conversely, Dobrovolskaia et al. (12) demon- strated that conditioning with LPS from Escherichia coli and challenge with LPS from Porphyromonas gingivalis (a TLR2 agonist) were not able to reduce the production of TNF- $\alpha$ in peritoneal macrophages of mice, the same occurring when the cells were conditioned with E. coli LPS and challenged with Pam3Cys (a TLR2/1 agonist) (12).

Conditioning with LPS did not change the production of IL-6 after a challenge with flagellin (a TLR5 agonist). A possible explanation for the lack of tolerance is the use of an alternative pathway of cell signaling by flagellin that was not inhibited by pre-exposure to LPS. One possibility that may be considered is the recognition of flagellin directly in the cytoplasm of the cell by Ipaf, a NOD like-receptor,
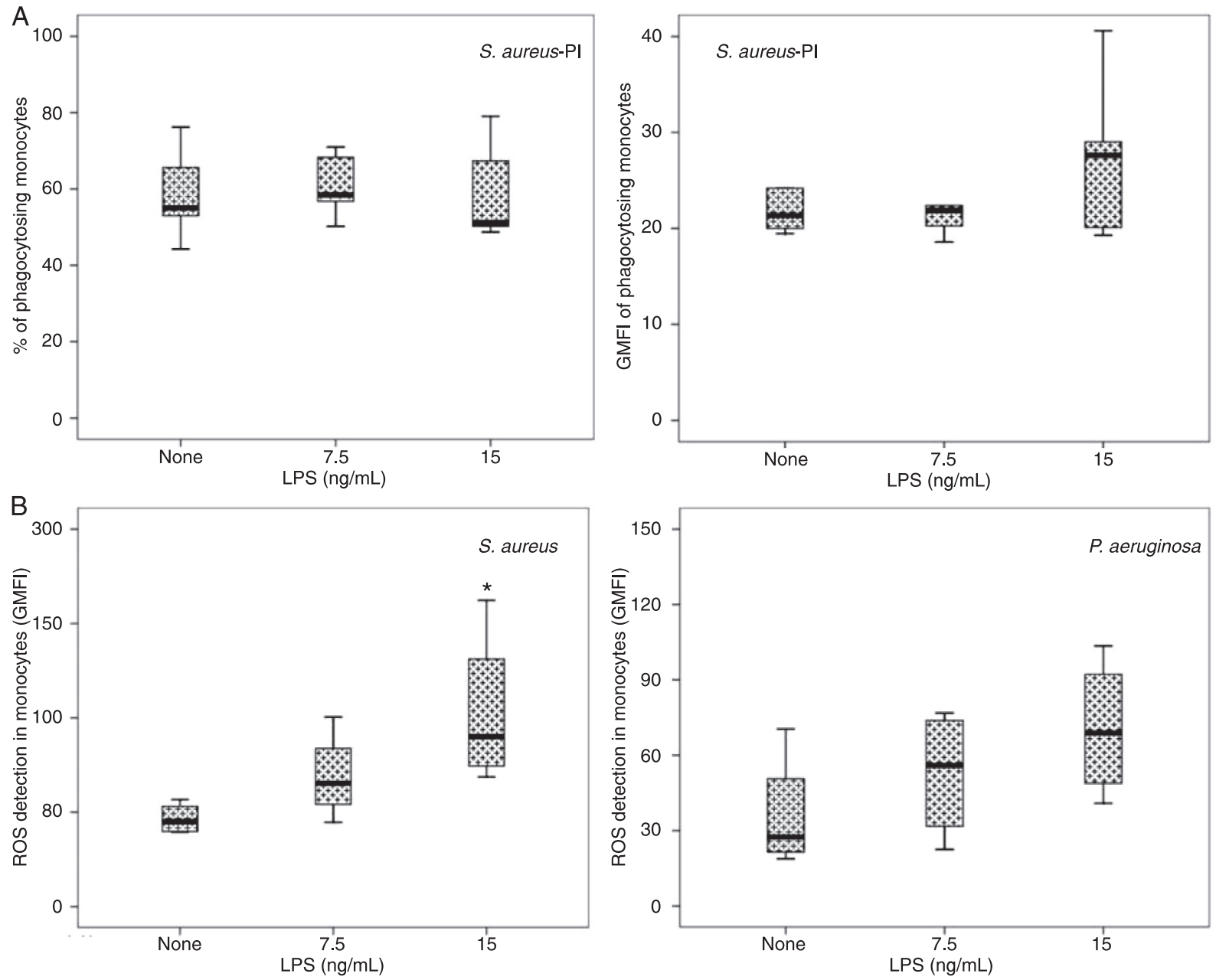

Figure 3. Phagocytosis and reactive oxygen species (ROS) generation by human tolerant monocytes. For monocyte phagocytosis, whole blood was stimulated for 30 min with S. aureus-propidium iodide (PI) after pretreatment with or without lipopolysaccharide (LPS; control). Monocyte phagocytosis was shown as the percentage of stained cells (A, left) and as the geometric mean of the fluorescence intensity (GMFI) (A, right). For induction of ROS, whole blood was stimulated for 30 min with $24 \times 10^{6} / \mathrm{mL}$ Staphylococcus aureus (B, left) and $12 \times 10^{6} / \mathrm{mL}$ Pseudomonas aeruginosa (B, right) after pretreatment with or without LPS (control). ROS production was measured by flow cytometry using 2',7'-dichlorofluorescein-diacetate detection. ${ }^{*} \mathrm{P}=0.05$ compared to no pretreatment (ANOVA followed by the Bonferroni's test). $\mathrm{N}=5$ for three different experiments. 
which activates the caspase- 1 and triggers the release of inflammatory cytokines $(31,32)$. Thus, cross-tolerance seems to depend on the cell type studied, the model used, and the concentration, sequence of conditioning and the stimulus.

After evaluating the modulatory effect of pre-exposure to LPS on the induction of IL- 6 by TLR4, TLR2/6 and TLR5 agonists, we assessed the effects of pre-exposure to LPS on the response to Gram-positive and Gram-negative bacteria, where multiple mechanisms of cellular activation are present. We chose to use S. aureus (a Gram-positive bacterium) and $P$. aeruginosa (a Gram-negative bacterium), common agents of infections in patients admitted to intensive care units (33).

Conditioning with increasing concentrations of LPS resulted in the detection of lower amounts of IL-6 in monocytes challenged with Staphylococcus aureus. This result agrees with Kreutz et al. (34) who showed induction of cross-tolerance between LPS and $S$. aureus in human monocytes by decreasing the production of TNF- $\alpha$. In contrast, Peck et al. (35) found increased production of TNF- $\alpha, I L-6, I L-8$, and IL-1 $\beta$ and unchanged production of granulocyte macrophage colony-stimulating factor (GMCSF) in THP-1 cells conditioned with LPS and challenged with $S$. aureus.

The challenge with $P$. aeruginosa resulted in lower detection of intracellular IL-6 after conditioning with LPS in monocytes of peripheral blood. Corroborating these data, we found a lower production of TNF- $\alpha$ induced by $P$. aeruginosa in peripheral blood cells of septic patients compared to healthy volunteers (10). Thus, the modulation of cells of septic patients during infection again shows similarities with tolerance induced in whole blood in vitro.

In previous studies involving patients with severe sepsis and septic shock, we observed a dichotomy in mononuclear cell modulation, with lower production of inflammatory cytokines after stimulation with LPS, and preserved or increased production of ROS $(11,20)$. To check whether this phenomenon was also observed in monocytes of healthy volunteers conditioned in vitro with LPS, we assessed phagocytosis and ROS generation induced by challenge with LPS, $P$. aeruginosa and $S$. aureus. Pre-exposure to LPS did not alter the percentage of monocytes phagocytosing bacteria or the GMFI of positively stained cells, indicating that both the proportion of phagocytosing cells and the amount of phagocytosed bacteria are preserved.

\section{References}

1. Beutler B, Hoebe K, Du X, Ulevitch RJ. How we detect microbes and respond to them: the Toll-like receptors and their transducers. J Leukoc Biol 2003; 74: 479-485.

2. Freudenberg MA, Salomao R, Sing A, Mitov I, Galanos C. Reconciling the concepts of endotoxin sensitization and tolerance. Prog Clin Biol Res 1998; 397: 261-268.
Conditioning with LPS did not alter the production of ROS in monocytes challenged with $P$. aeruginosa or LPS, and an even increased production of ROS was detected in monocytes challenged with $S$. aureus. Thus, we demonstrated that monocytes of healthy individuals tolerant to LPS show the same dichotomy that we observed in septic patients. These results in humans are supported by experimental evidence showing that animals tolerant to LPS present preserved bacterial clearance (15), and preserved oxidative stress response and NO production (36). The presence of antimicrobial peptides produced by cells during sepsis or after exposure to LPS in vitro could support these findings. It has been shown that pre-incubation with antimicrobial peptides increases respiratory burst in murine (RAW 264.7) and human (THP-1) macrophage-like cell lines, while inhibiting the release of TNF- $\alpha$ and NO induced by LPS (37). Our results also corroborated the findings of del Fresno et al. (38) who showed that human monocytes made tolerant to LPS and monocytes isolated from cystic fibrosis patients had high phagocytic activity and low production of inflammatory cytokines. This dichotomy fits the concept of Foster and co-workers (29) that gene regulation in cells made tolerant to LPS falls into two classes, the tolerizeable (T) and non-tolerizeable (NT) genes. The T genes, which are associated with pro-inflammatory genes, are down-regulated to protect against tissue damage, and the NT genes, which are associated with antimicrobial genes, remain inducible to protect against the microbes (29).

In conclusion, the phenomenon of tolerance in human whole blood monocytes encompasses up- and downregulation of cellular activity. Decreased production of proinflammatory cytokines and preserved or increased production of ROS may be an adaptation driven to control the deleterious effects of inflammation, while preserving antimicrobial activity, corroborating a previous study on gene expression in tolerant cells (29). The similarities between the changes found in leukocytes of septic patients and in cells made tolerant to LPS in vitro indicate that this approach may be valuable for the understanding of the modulation of LPS-induced cell signaling during sepsis.

\section{Acknowledgments}

The authors thank Maria Aparecida Dalboni for kindly providing the PI-labeled Staphylococcus aureus. Research supported by FAPESP (\#2006/58744-1).
3. Cavaillon JM, Adib-Conquy M. Bench-to-bedside review: endotoxin tolerance as a model of leukocyte reprogramming in sepsis. Crit Care 2006; 10: 233.

4. Granowitz EV, Porat R, Mier JW, Orencole SF, Kaplanski $G$, Lynch EA, et al. Intravenous endotoxin suppresses the cytokine response of peripheral blood mononuclear cells of 
healthy humans. J Immunol 1993; 151: 1637-1645.

5. van der Poll T, Coyle SM, Moldawer LL, Lowry SF. Changes in endotoxin-induced cytokine production by whole blood after in vivo exposure of normal humans to endotoxin. $J$ Infect Dis 1996; 174: 1356-1360.

6. Tominaga K, Saito S, Matsuura M, Nakano M. Lipopolysaccharide tolerance in murine peritoneal macrophages induces downregulation of the lipopolysaccharide signal transduction pathway through mitogen-activated protein kinase and nuclear factor-kappaB cascades, but not lipopolysaccharide-incorporation steps. Biochim Biophys Acta 1999; 1450: 130-144.

7. Dobrovolskaia MA, Vogel SN. Toll receptors, CD14, and macrophage activation and deactivation by LPS. Microbes Infect 2002; 4: 903-914.

8. Ertel W, Kremer JP, Kenney J, Steckholzer U, Jarrar D, Trentz O, et al. Downregulation of proinflammatory cytokine release in whole blood from septic patients. Blood 1995; 85: 1341-1347.

9. Ertel W, Keel M, Neidhardt R, Steckholzer U, Kremer JP, Ungethuem $U$, et al. Inhibition of the defense system stimulating interleukin-12 interferon-gamma pathway during critical illness. Blood 1997; 89: 1612-1620.

10. Rigato O, Salomao R. Impaired production of interferongamma and tumor necrosis factor-alpha but not of interleukin 10 in whole blood of patients with sepsis. Shock 2003; 19: $113-116$

11. Brunialti MK, Martins PS, Barbosa de $\mathrm{CH}$, Machado $\mathrm{FR}$, Barbosa LM, Salomao R. TLR2, TLR4, CD14, CD11B, and CD11C expressions on monocytes surface and cytokine production in patients with sepsis, severe sepsis, and septic shock. Shock 2006; 25: 351-357.

12. Dobrovolskaia MA, Medvedev AE, Thomas KE, Cuesta $\mathrm{N}$, Toshchakov $\mathrm{V}$, Ren $\mathrm{T}$, et al. Induction of in vitro reprogramming by Toll-like receptor (TLR)2 and TLR4 agonists in murine macrophages: effects of TLR "homotolerance" versus "heterotolerance" on NF-kappa B signaling pathway components. J Immunol 2003; 170: 508-519.

13. Medvedev AE, Kopydlowski KM, Vogel SN. Inhibition of lipopolysaccharide-induced signal transduction in endotoxin-tolerized mouse macrophages: dysregulation of cytokine, chemokine, and Toll-like receptor 2 and 4 gene expression. $\mathrm{J}$ Immunol 2000; 164: 5564-5574.

14. Lehner MD, Morath S, Michelsen KS, Schumann RR, Hartung $T$. Induction of cross-tolerance by lipopolysaccharide and highly purified lipoteichoic acid via different Toll-like receptors independent of paracrine mediators. J Immunol 2001; 166: 5161-5167.

15. Wheeler DS, Lahni PM, Denenberg AG, Poynter SE, Wong $\mathrm{HR}$, Cook JA, et al. Induction of endotoxin tolerance enhances bacterial clearance and survival in murine polymicrobial sepsis. Shock 2008; 30: 267-273.

16. Murphey ED, Fang G, Sherwood ER. Endotoxin pretreatment improves bacterial clearance and decreases mortality in mice challenged with Staphylococcus aureus. Shock 2008; 29: 512-518.

17. Severn A, Xu D, Doyle J, Leal LM, O'Donnell CA, Brett SJ, et al. Pre-exposure of murine macrophages to lipopolysaccharide inhibits the induction of nitric oxide synthase and reduces leishmanicidal activity. Eur J Immunol 1993; 23: 1711-1714.

18. Zingarelli B, Halushka PV, Caputi AP, Cook JA. Increased nitric oxide synthesis during the development of endotoxin tolerance. Shock 1995; 3: 102-108.

19. Fahmi H, Charon D, Mondange M, Chaby R. Endotoxininduced desensitization of mouse macrophages is mediated in part by nitric oxide production. Infect Immun 1995; 63: 1863-1869.

20. Martins PS, Brunialti MK, Martos LS, Machado FR, Assuncao MS, Blecher S, et al. Expression of cell surface receptors and oxidative metabolism modulation in the clinical continuum of sepsis. Crit Care 2008; 12: R25.

21. Galanos C, Luderitz O, Westphal O. Preparation and properties of a standardized lipopolysaccharide from Salmonella abortus equi (Novo-Pyrexal). Zentralbl Bakteriol Orig A 1979; 243: 226-244.

22. Opal SM. Tumor necrosis factor receptor expression on inflammatory cells in sepsis. Crit Care Med 1999; 27: 240241.

23. Hiki N, Berger D, Dentener MA, Mimura Y, Buurman WA, Prigl $C$, et al. Changes in endotoxin-binding proteins during major elective surgery: important role for soluble CD14 in regulation of biological activity of systemic endotoxin. Clin Diagn Lab Immunol 1999; 6: 844-850.

24. Nomura F, Mukai S, Fumimoto Y, Shimazutsu K, Ihara K. Reliable and cost-effective system for surgical stent graft insertion. Ann Thorac Surg 2000; 70: 2171-2172.

25. Salomao R, Brunialti MK, Kallas EG, Martins PS, Rigato $\mathrm{O}$, Freudenberg M. Lipopolysaccharide-cell interaction and induced cellular activation in whole blood of septic patients. J Endotoxin Res 2002; 8: 371-379.

26. Salomao R, Martins PS, Brunialti MK, Fernandes ML, Martos LS, Mendes ME, et al. TLR signaling pathway in patients with sepsis. Shock 2008; 30 (Suppl 1): 73-77.

27. Biswas SK, Lopez-Collazo E. Endotoxin tolerance: new mechanisms, molecules and clinical significance. Trends Immunol 2009; 30: 475-487.

28. Beutler B. Innate immunity: an overview. Mol Immunol 2004; 40: 845-859.

29. Foster SL, Hargreaves DC, Medzhitov R. Gene-specific control of inflammation by TLR-induced chromatin modifications. Nature 2007; 447: 972-978.

30. Sato S, Nomura F, Kawai T, Takeuchi O, Muhlradt PF, Takeda K, et al. Synergy and cross-tolerance between Toll-like receptor (TLR) 2- and TLR4-mediated signaling pathways. J Immunol 2000; 165: 7096-7101.

31. Miao EA, Alpuche-Aranda CM, Dors M, Clark AE, Bader MW, Miller SI, et al. Cytoplasmic flagellin activates caspase-1 and secretion of interleukin 1 beta via Ipaf. Nat Immunol 2006; 7 : 569-575.

32. Miao EA, Andersen-Nissen E, Warren SE, Aderem A. TLR5 and Ipaf: dual sensors of bacterial flagellin in the innate immune system. Semin Immunopathol 2007; 29: 275-288.

33. Cagatay AA, Ozcan PE, Gulec L, Ince N, Tugrul S, Ozsut H, et al. Risk factors for mortality of nosocomial bacteraemia in intensive care units. Med Princ Pract 2007; 16: 187-192.

34. Kreutz M, Ackermann U, Hauschildt S, Krause SW, Riedel $\mathrm{D}$, Bessler W, et al. A comparative analysis of cytokine production and tolerance induction by bacterial lipopeptides, lipopolysaccharides and Staphyloccous aureus in human monocytes. Immunology 1997; 92: 396-401.

35. Peck OM, Williams DL, Breuel KF, Kalbfleisch JH, Fan H, Tempel GE, et al. Differential regulation of cytokine and chemokine production in lipopolysaccharide-induced toler- 
ance and priming. Cytokine 2004; 26: 202-208.

36. Melo ES, Barbeiro HV, Ariga S, Goloubkova T, Curi R, Velasco IT, et al. Immune cells and oxidative stress in the endotoxin tolerance mouse model. Braz J Med Biol Res 2010; 43: 57-67.

37. Zughaier SM, Shafer WM, Stephens DS. Antimicrobial peptides and endotoxin inhibit cytokine and nitric oxide release but amplify respiratory burst response in human and murine macrophages. Cell Microbiol 2005; 7: 1251-1262.

38. del Fresno C, Garcia-Rio F, Gomez-Pina V, Soares-Schanoski A, Fernandez-Ruiz I, Jurado T, et al. Potent phagocytic activity with impaired antigen presentation identifying lipopolysaccharide-tolerant human monocytes: demonstration in isolated monocytes from cystic fibrosis patients. $J$ Immunol 2009; 182: 6494-6507. 